\title{
Periodic Swelling and Collapse of Polyelectrolyte Brushes Driven by Chemical Oscillation
}

\author{
Guangming Liu and Guangzhao Zhang* \\ Hefei National Laboratory for Physical Sciences at Microscale, Department of Chemical Physics, University of \\ Science and Technology of China, Hefei, China
}

Received: February 20, 2008; Revised Manuscript Received: June 17, 2008

\begin{abstract}
Poly(acrylic acid) (PAA) chains exhibit conformational change in response to $\mathrm{pH}$, whereas bromate-sulfiteferrocyanide (BSF) solution shows pH oscillation between 3.2 and 6.6. By use of quartz crystal microbalance with dissipation (QCM-D), we have investigated the $\mathrm{pH}$ induced conformational change of PAA brushes under a continuous flow of BSF solution in real time. The changes in frequency and dissipation clearly indicate the periodic swelling and collapse of brushes with $\mathrm{pH}$ oscillation. The changes in thickness, viscosity, and elastic modulus further indicate the oscillation of the interface.
\end{abstract}

\section{Introduction}

Many physiological behaviors such as heartbeat and brainwaves exhibit rhythmical oscillations. Unlike conventional stimuli-responsive materials which act in an equilibrium state, ${ }^{1,2}$ such a living system works in a nonequilibrium state. No doubt, biomimetic systems with rhythmical action can not only help us to understand nonequilibrium thermodynamics and phenomena in life but find applications in nanodevices, biomaterials and drug delivery. In the past years, self-oscillating polymer gels,${ }^{3}$ free polymer chains, ${ }^{4}$ and immobilized macromolecules ${ }^{5}$ have been prepared. These materials work in a closed system driven by the Belousov-Zhabotinsky reaction, so the oscillation amplitude decays with time. In parallel, oscillations of some polymer gels ${ }^{6,7}$ and $\mathrm{DNA}^{8}$ have also been achieved in an open system driven by the Landolt reaction, whose amplitude holds a constant due to the continuous input. Obviously, the latter is more analogous to a physiological system, namely, the oscillation has invariant amplitude under a constant input.

Note that interface or surface plays an important role in organs and materials. So far, the oscillating interface or surface has been seldom studied because it is still a hard work to characterize such an oscillation in situ. Interfaces modified with polymer nanofilms have attached extensive attentions due to their potential applications in biosensors, ${ }^{9}$ colloidal stabilization, ${ }^{10}$ and porous membrane. ${ }^{11}$ Nevertheless, the external stimulation in these studies was usually manually varied so that the interface properties could be switched. This will limit their applications. For example, the continuous motion of nanoobjects driven by polymer brushes can not be achieved in such a procedure. ${ }^{12}$ To solve this problem, polymer brushes should be constructed with a free running motor to generate the continuous output of mechanical energy. Polyelectrolyte brushes with $\mathrm{pH}$ response driven by the Landolt reaction make such a continuous switch possible.

In the present study, we have created a soft interface by poly(acrylic acid) (PAA) brushes with a good biocompatibility, ${ }^{13}$ and fabricated them with a Landolt oscillator. Considering that quartz crystal microbalance with dissipation (QCM-D) can sensitively detect the changes in mass and structure of a layer at interface, ${ }^{14}$ for the first time, we have investigated the $\mathrm{pH}$

* To whom correspondence should be addressed. E-mail: gzzhang@ ustc.edu.cn. induced oscillation of PAA brushes at the solid/liquid interface in real time. Our aim is to understand how an interface consisting of polymer brushes to oscillate.

\section{Experimental Section}

Materials. Sodium acrylate (97\%, Aldrich), copper(I) bromide $\left(\mathrm{CuBr}, 98 \%\right.$, Aldrich), copper(II) bromide $\left(\mathrm{CuBr}_{2}, 99 \%\right.$, Alfa), and 2,2'-bipyridine (99\%, Alfa) were all used as received. 11-mercaptoundecyl bromoisobutyrate $\left(\mathrm{HS}\left(\mathrm{CH}_{2}\right)_{11} \mathrm{OOC}\left(\mathrm{CH}_{3}\right)_{2}\right.$ $\mathrm{CBr}$ ) was purchased from Beijing HRBio Biotechnology Co. Potassium hexacyanoferrate(II) trihydrate $\left(\mathrm{K}_{4}\left[\mathrm{Fe}(\mathrm{CN})_{6}\right] \cdot 3 \mathrm{H}_{2} \mathrm{O}\right.$, $99.5 \%)$, sodium sulfite anhydrous $\left(\mathrm{Na}_{2} \mathrm{SO}_{3}, 97 \%\right)$, potassium bromate $\left(\mathrm{KBrO}_{3}, 99.8 \%\right)$, and sulfuric acid $\left(\mathrm{H}_{2} \mathrm{SO}_{4}, 98 \%\right)$ were all purchased from Sinopharm Chemical Reagent Co. Milli-Q water was used for preparation of bromate-sulfite-ferrocyanide solution. All other regents were used as received.

Preparation of PAA Brushes. The gold-coated resonator was cleaned by using Piranha solution composed of one part $\mathrm{H}_{2} \mathrm{O}_{2}$ and three parts $\mathrm{H}_{2} \mathrm{SO}_{4}$ at $70{ }^{\circ} \mathrm{C}$ for $20 \mathrm{~min}$, rinsed with Milli-Q water, and blown dry with $\mathrm{N}_{2}$. The monolayer of initiator was prepared by placing the resonator with one side covered with a protective casing made of Teflon in a $1.0 \mathrm{mM}$ solution of $\mathrm{HS}\left(\mathrm{CH}_{2}\right)_{11} \mathrm{OOC}\left(\mathrm{CH}_{3}\right)_{2} \mathrm{CBr}$ in anhydrous ethanol under a continuous nitrogen purge for $\sim 14 \mathrm{~h}$. Then, the resonator was rinsed with ethanol, dried with flowing nitrogen, and used immediately for the polymerization experiment.

Poly(sodium acrylate) (PSA) brushes were prepared by surface-initiated atom transfer radical polymerization (SIATRP). Typically, sodium acrylate (2.0 g), 2,2'-bipyridine (137 $\mathrm{mg}$ ), and $10 \mathrm{~mL}$ of water were added to a flask equipped with a magnetic stir bar. The solution was degassed by four freeze-pump - thaw cycles to remove the oxygen. Then, $\mathrm{CuBr}$ (58 mg) and $\mathrm{CuBr}_{2}(9 \mathrm{mg})$ were added to the flask under the protection of $\mathrm{N}_{2}$. The mixture was stirred at $25^{\circ} \mathrm{C}$ under $\mathrm{N}_{2}$ for $\sim 10 \mathrm{~min}$. The initiator-modified resonator was placed inside the flask under the protection of $\mathrm{N}_{2}$. After the polymerization proceeded at $25{ }^{\circ} \mathrm{C}$ for $\sim 22 \mathrm{~h}$, the resonator was taken out, washed with water, and dried with a stream of $\mathrm{N}_{2}$.

Atomic Force Microscopy (AFM) Measurements. PAA layer formed on the gold-coated resonator surface was imaged on AFM (Nanoscope IIIa, DI) in air. The AFM tip was used to selectively scratch the layer, and the thickness of the PAA layer in the dry state evaluated by section analysis of AFM height image. 
X-ray Photoelectron Spectroscopy (XPS) Measurements. XPS measurements were conducted on an ESCALAB-250 spectrometer with a monochromatic $\mathrm{Al} \mathrm{K} \alpha \mathrm{X}$-ray source $(\mathrm{h} v$ $=1486.6 \mathrm{eV}$ ). The spot size is $500 \mathrm{um}$. XPS spectra were collected at an emission angle of $0^{\circ}$ with respect to the surface normal (a take off angle of $90^{\circ}$ ). The analyzer was operated in constant resolution mode at pass energy of $20 \mathrm{eV}$. During XPS measurement, surface charging was compensated by using a flood gun. All binding energies were obtained by setting the $\mathrm{C}_{1 \mathrm{~s}}$ contamination line at $284.6-285.0 \mathrm{eV}$ as the reference.

QCM-D Measurements. QCM-D with an AT-cut crystal was from Q-sense $\mathrm{AB}$. The fundamental resonant frequency of the crystal was $5 \mathrm{MHz}$. The crystal was mounted in a fluid cell with one side exposed to the solution. ${ }^{15}$ The constant $(C)$ of the crystal was $17.7 \mathrm{ng} / \mathrm{cm}^{2} \mathrm{~Hz}$. The measurable frequency shift was within $\pm 1 \mathrm{~Hz}$ in aqueous medium. A quartz crystal is excited to oscillate in the thickness shear mode at its fundamental resonant frequency $\left(f_{0}\right)$ when a RF voltage near the resonant frequency is applied across the electrodes. A small layer added to the electrodes would induce a decrease in resonant frequency $(\Delta f)$, which is proportional to the mass $(\Delta m)$ of the layer. In vacuum or air, if the added layer is rigid, evenly distributed and much thinner than the crystal, $\Delta f$ is related to $\Delta m$ and the overtone number $(n=1,3,5, \ldots)$ by the Sauerbrey equation ${ }^{16}$

$$
\Delta m=-\frac{\rho_{q} l_{q}}{f_{\mathrm{o}}} \frac{\Delta f}{n}
$$

where $f_{0}$ is the fundamental frequency, $\rho_{q}$ and $l_{q}$ are the specific density and thickness of the quartz crystal, respectively. The dissipation factor (D) is defined by

$$
\mathrm{D}=\frac{E_{\text {dissipated }}}{2 \pi E_{\text {stored }}}
$$

where $E_{\text {disspated }}$ is the energy dissipated during one oscillation and $E_{\text {stored }}$ is the energy stored in the oscillating system. D is measured based on the fact that the voltage over the crystal decays exponentially as a damped sinusoidal when the driving power of a piezoelectric oscillator is switched off. ${ }^{15} \mathrm{By}$ switching the driving voltage on and off periodically, we can simultaneously obtain a series of the changes of the resonant frequency and the dissipation factor. $\Delta f$ and $\Delta D$ values from the fundamental were usually noisy because of insufficient energy trapping and thus discarded. ${ }^{17}$ All experiments were performed at $25 \pm 0.02{ }^{\circ} \mathrm{C}$.

\section{Results and Discussion}

Poly(sodium acrylate) (PSA) chains were grafted onto QCM-D resonator surface by surface-initiated atom transfer radical polymerization. ${ }^{18}$ The preparation is illustrated in Figure 1a. The wash of PSA chains with Milli-Q water yielded PAA chains, which was confirmed by XPS (Figure 2). The thickness of PAA layer in a dry state was $\sim 10 \mathrm{~nm}$ obtained by AFM section analysis (Figure 1b), where AFM tip was used to selectively scratch the layer. The thickness $(t)$ of PAA layer in swollen state in water was estimated to be $\sim 20 \mathrm{~nm}$ by QCM-D based on the Voigt model. ${ }^{19}$ In the present work, the distance (d) between two grafting sites was estimated to be $\sim 0.5 \mathrm{~nm}$ based on the self-assembled monolayer chain density on a gold surface. ${ }^{20}$ Since $t \gg d$, the tethered PAA chains are expected to form brushes. In addition, the root-mean-square (rms) roughness of PAA layer is $\sim 3 \mathrm{~nm}$ estimated from the AFM image. Therefore, the effect of the layer roughness on QCM-D

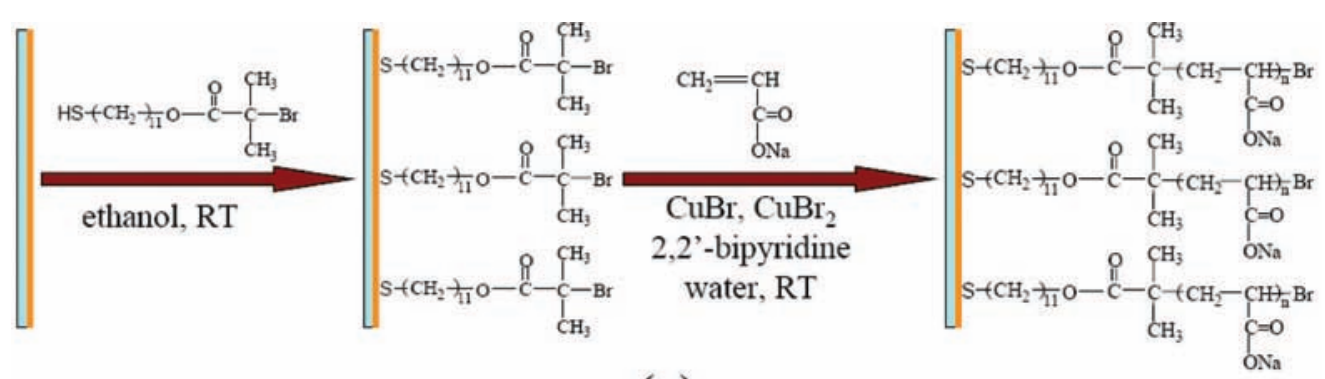

(a)

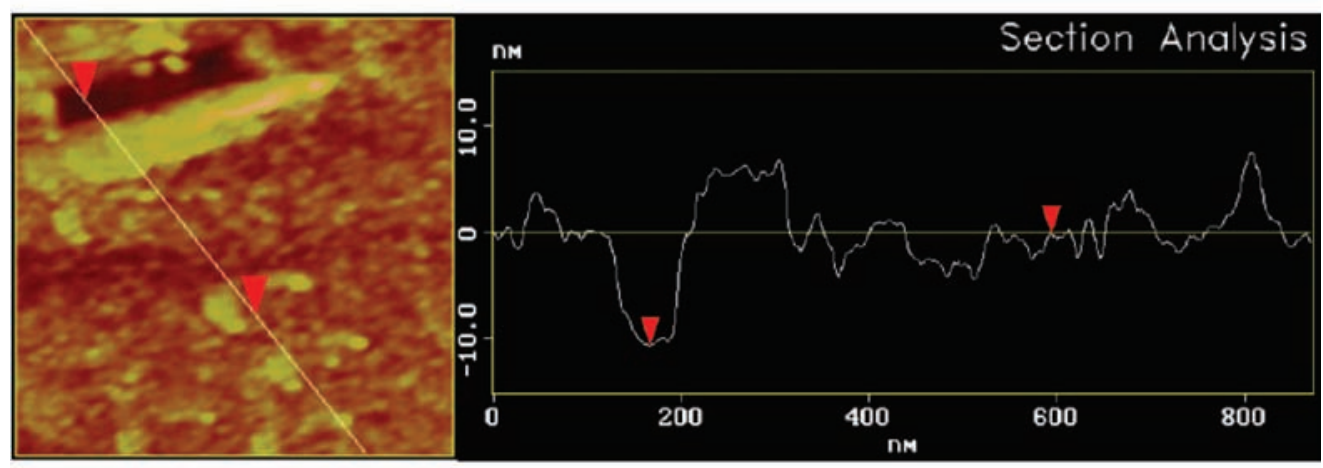

(b)

Figure 1. (a) Grafting of PSA chains on resonator surface by SI-ATRP. The monolayer of initiator was prepared by placing the resonator in anhydrous ethanol solution of $\mathrm{HS}\left(\mathrm{CH}_{2}\right)_{11} \mathrm{OOC}\left(\mathrm{CH}_{3}\right)_{2} \mathrm{CBr}$. (b) The thickness of PAA layer in a dry state evaluated by the section analysis of AFM image. The AFM tip was used to selectively scratch the layer, and the thickness of the PAA layer in the dry state was evaluated by AFM. 


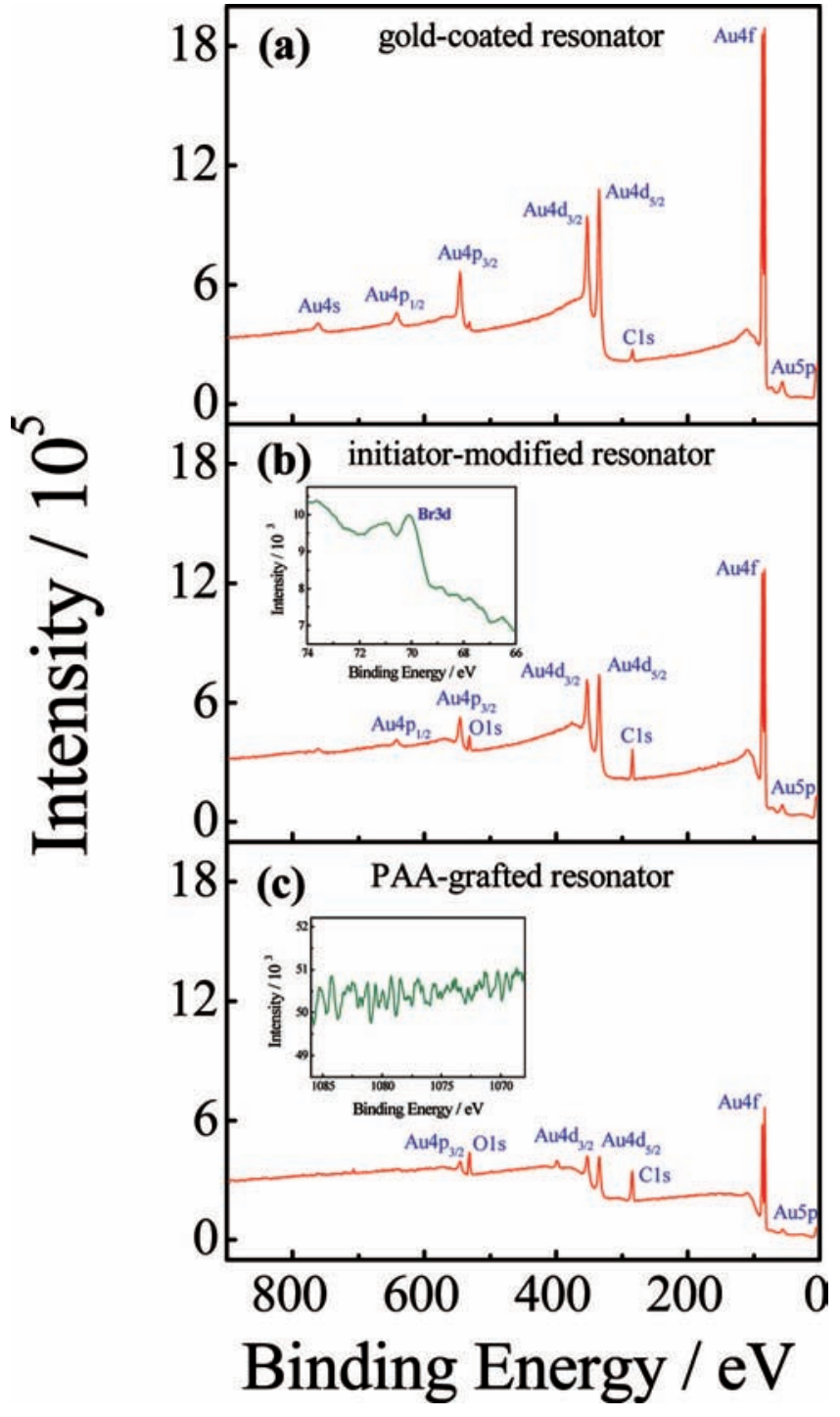

Figure 2. (a) XPS spectrum of gold-coated resonator. (b) XPS spectrum of initiator-modified resonator. (c) XPS spectrum of PAAgrafted resonator.

responses can be neglected. ${ }^{21}$ The experiments were performed by immersing the QCM-D resonator grafted with PAA brushes in the cell under a continuous flow of bromate-sulfiteferrocyanide (BSF) solution consisting of $\mathrm{KBrO}_{3}, \mathrm{Na}_{2} \mathrm{SO}_{3}$, $\mathrm{K}_{4}\left[\mathrm{Fe}(\mathrm{CN})_{6}\right]$, and $\mathrm{H}_{2} \mathrm{SO}_{4}$ at $25{ }^{\circ} \mathrm{C}$.

Figure 2 shows the XPS spectra of gold-coated resonator (a), initiator-modified resonator (b) and PAA-grafted resonator (c). The intensities of all Au peaks gradually decrease from part a to part $\mathrm{c}$, indicating that the thickness and coverage of the layer on resonator surface increase. The small peak of $\mathrm{C}_{1 \mathrm{~s}}$ in Figure $2 \mathrm{a}$ is attributed to the trace contaminant. The peaks of $\mathrm{O}_{1 \mathrm{~s}}$ and $\mathrm{C}_{1 \mathrm{~s}}$ in Figure $2 \mathrm{~b}$ imply that the initiator molecules attached onto the resonator surface. This can be further confirmed from the inset in Figure $2 \mathrm{~b}$, where a $\mathrm{Br}_{3 \mathrm{~d}}$ peak is observed at $\sim 70 \mathrm{ev}$. Figure 2c shows the intensity of $\mathrm{O}_{1 \mathrm{~s}}$ becomes much stronger than that in Figure $2 \mathrm{~b}$ indicating the formation of PAA layer on the resonator surface. The ratio of $\mathrm{C} / \mathrm{O}$ was estimated to be $3: 1$, which is some larger than the element composition of PAA. The excessive carbon can be attributed to the trace contaminant. The inset in Figure 2c shows the absence of sodium (1072 ev) in XPS spectrum, indicating that the carboxylate anions were fully protonated during the wash of PSA layer with water. In

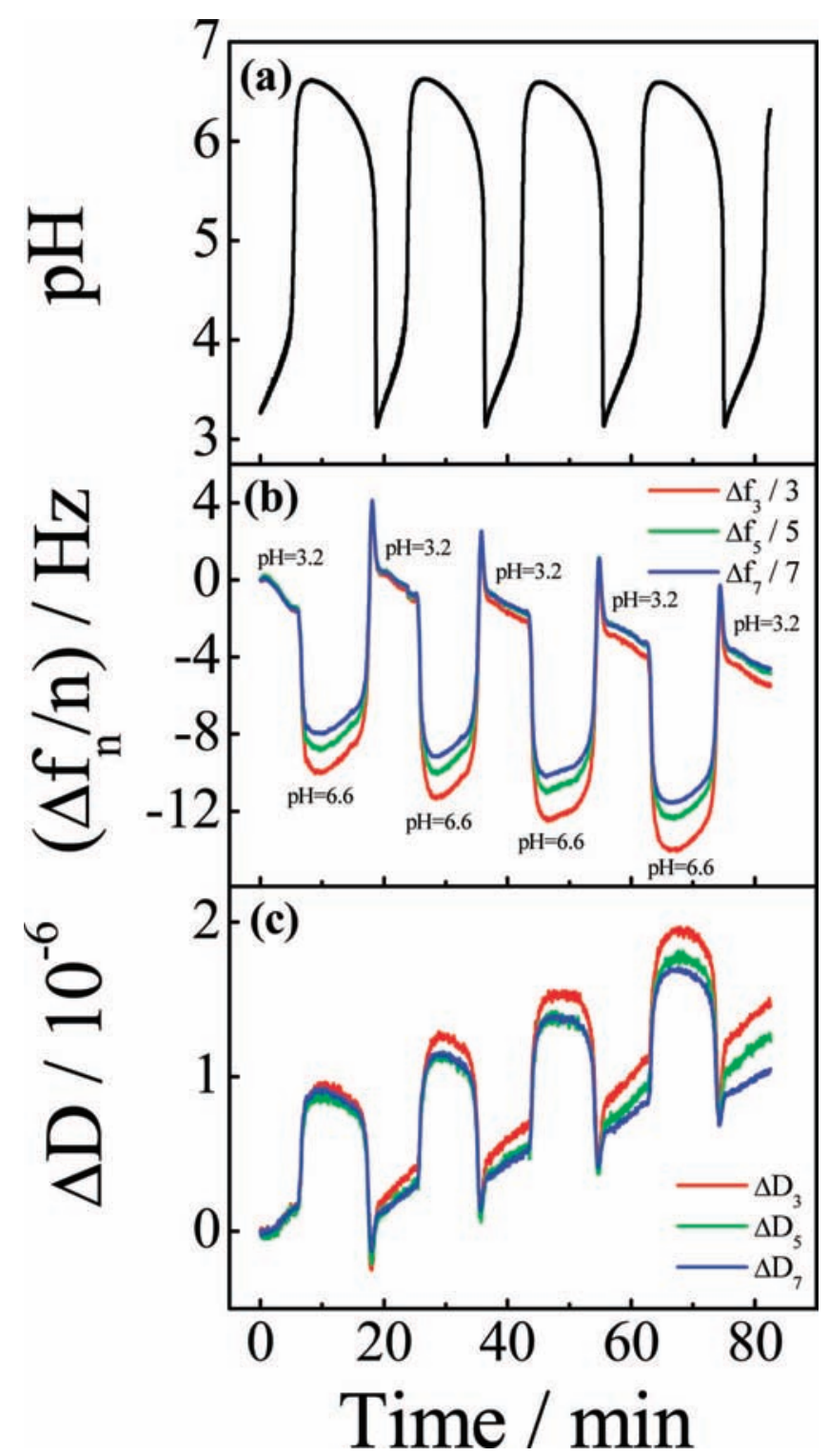

Figure 3. (a) Oscillation of $\mathrm{pH}$ of $\mathrm{BSF}$ solution, where $\left[\mathrm{KBrO}_{3}\right]=$ $0.065 \mathrm{M},\left[\mathrm{Na}_{2} \mathrm{SO}_{3}\right]=0.075 \mathrm{M}, \mathrm{K}_{4}\left[\mathrm{Fe}(\mathrm{CN})_{6}\right]=0.02 \mathrm{M},\left[\mathrm{H}_{2} \mathrm{SO}_{4}\right]=$ 0.01 M. (b) Time dependence of changes of frequency $(\Delta f)$ of PAA brushes under a continuous flow of BSF solution, where the overtone number $n=3,5,7$. (c) Time dependence of changes of dissipation $(\Delta D)$ of PAA brushes under a continuous flow of BSF solution, where the overtone number $n=3,5,7$. All the measurements were conducted at $25^{\circ} \mathrm{C}$ with the flow rate $\left(V_{f r}\right)$ of BSF solution being $1.4 \mathrm{~mL} / \mathrm{min}$.

other words, PSA was changed into PAA. The peaks of Au in Figure $2 \mathrm{c}$ are attributed to the gold surface uncovered by PAA layer.

Figure 3a shows the time dependence of $\mathrm{pH}$ of BSF solution. The reaction was conducted in a continuously stirred tank reactor (CSTR), with a continuous flow in and out of the solution to keep the volume constant. ${ }^{7 \mathrm{a}} \mathrm{pH}$ was measured by a MettlerToledo $\mathrm{pH}$ meter in real time before the solution flowed into QCM-D cell. The optimum flow rate for reliable oscillations in QCM-D measurements was $1.4 \mathrm{~mL} / \mathrm{min}$ with a constant composition of $\left[\mathrm{KBrO}_{3}\right]=0.065 \mathrm{M},\left[\mathrm{Na}_{2} \mathrm{SO}_{3}\right]=0.075 \mathrm{M}$, $\mathrm{K}_{4}\left[\mathrm{Fe}(\mathrm{CN})_{6}\right]=0.02 \mathrm{M}$, and $\left[\mathrm{H}_{2} \mathrm{SO}_{4}\right]=0.01 \mathrm{M}$. Typically, $\mathrm{pH}$ was varied between 3.2 and 6.6 with an oscillation period for $\sim 20 \mathrm{~min}$ at a flow rate $\left(V_{f r}\right)$ of $1.4 \mathrm{~mL} / \mathrm{min}$. In principle, $\mathrm{pH}$ can have an infinite number of oscillations with the continuous flow. 


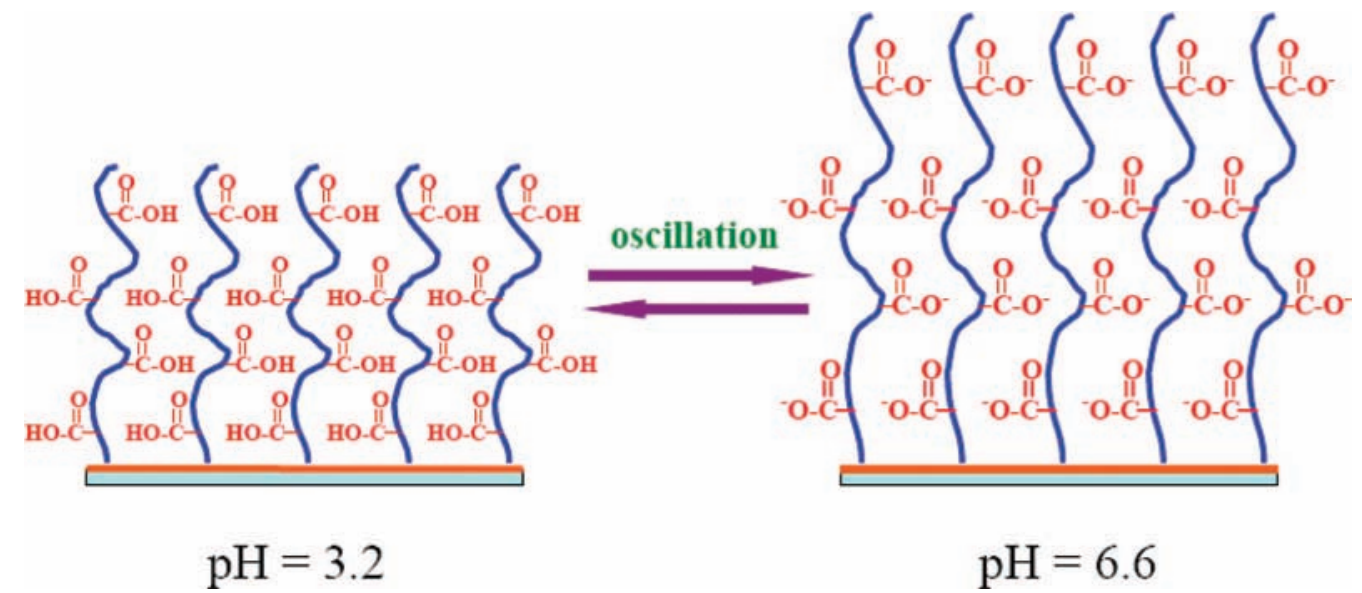

Figure 4. Oscillation of PAA brushes. The $\mathrm{p} K_{\mathrm{a}}$ of PAA is 4.5 , namely, the carboxyl groups will associate with protons below $\mathrm{pH} 4.5$ and the same groups will dissociate above this $\mathrm{pH}$. In the dissociation state, there will be stronger interactions between carboxyl groups and water molecules resulting in greater swelling of the grafted PAA layer and vice versa.

Parts $\mathrm{b}$ and $\mathrm{c}$ of Figure 3 show the time dependence of changes in frequency $(\Delta f)$ and dissipation $(\Delta D)$ of PAA brushes under a continuous flow of BSF solution at $V_{f r}=1.4 \mathrm{~mL} / \mathrm{min}$. Clearly, both $\Delta f$ and $\Delta D$ exhibit marked oscillations. As $\mathrm{pH}$ increases from 3.2 to $6.6, \Delta f$ rapidly decreases. Then, $\Delta f$ sharply increases as $\mathrm{pH}$ varies from 6.6 to 3.2. In contrast, the response of dissipation oscillates with $\mathrm{pH}$ in an opposite trend. What concerns us is the $\mathrm{pH}$ effect on the conformational change of PAA chains. PAA is a weak polyelectrolyte with $\mathrm{p} K_{\mathrm{a}} \sim 4.5,{ }^{22}$ that is, PAA chains have a lower and higher charge density at $\mathrm{pH}<4.5$ and $\mathrm{pH}>4.5$, respectively. It is known that $\Delta f$ is the response of the mass or thickness of the layer on resonator surface, whereas $\Delta D$ reflects the structure of the layer. ${ }^{19}$ As $\mathrm{pH}$ increases from 3.2 to 6.6 , the carboxyl groups are more ionized, so more water molecules are coupled with PAA chains, leading $\Delta f$ to decrease. Meanwhile, as $\mathrm{pH}$ increases, electrostatic repulsive interactions between PAA chain segments become stronger, so that PAA chains tend to be stretched and the layer becomes thicker. This further leads $\Delta f$ to decrease. In contrast, as $\mathrm{pH}$ decreases from 6.6 to $3.2, \Delta f$ increases due to the dehydration of PAA chains and the decrease in thickness of PAA brushes. In addition, the overtone dependence of $\Delta f$ between $\mathrm{pH} 6.6$ and 3.2 indicates that the viscoelasticity of PAA brushes also oscillates with $\mathrm{pH} .{ }^{14}$ The slight overtone dependence at pH 3.2 implies PAA brushes are less viscoelastic, whereas the larger dependence at pH 6.6 indicates the brushes are more viscoelastic. This can be viewed more clearly from the change of $\Delta D$. As $\mathrm{pH}$ increases from 3.2 to $6.6, \Delta D$ increases indicating that more shear wave is damped by PAA brushes, namely, the brushes become more viscoelastic and hydrated. In contrast, the decrease of $\Delta D$ with $\mathrm{pH}$ varied from 6.6 to 3.2 indicates the collapse and dehydration of PAA brushes. Note that the spikes in the responses of frequency and dissipation are attributed to the small changes of density and viscosity in the solution (see Figure S-1 in the Supporting Information). Figure 4 describes the oscillation of PAA brushes. The brushes show similar oscillations at other flow rates (see Figures S-2 and S-3 in the Supporting Information). The above results also reveal that the response of PAA brushes is quick, and the amplitude of oscillation holds constant. The facts indicate that water molecules diffuse in and out of the brushes freely. Thus, the polyelectrolyte brushes are expected to exhibit better properties in practical applications than the chemical cross-linked polymer gels, whose response is limited by the diffusion of solvent molecules. ${ }^{7 \mathrm{c}}$

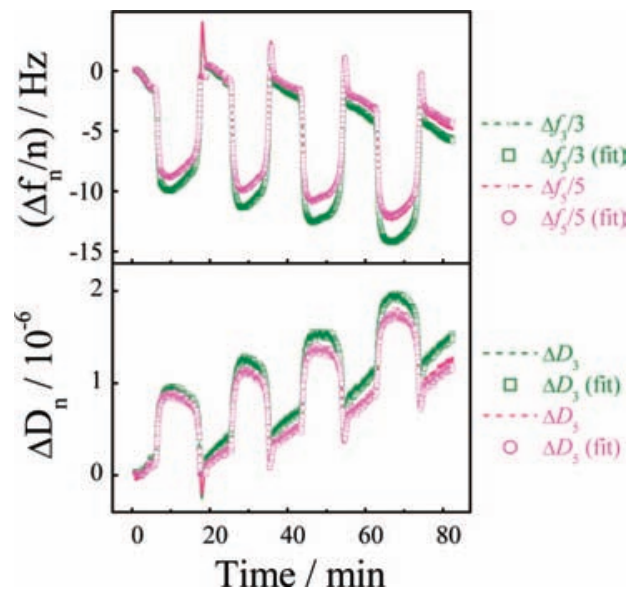

Figure 5. Time dependence of $\Delta f$ and $\Delta D$ fit by the Voigt model for $V_{f r}=1.4 \mathrm{~mL} / \mathrm{min}$ at the overtone number $n=3,5$.

Figure 5 shows $\Delta f$ and $\Delta D$ values during the oscillation were fit by theoretical representations based on Voigt model with Q-tools software, ${ }^{14}$ where $V_{f r}=1.4 \mathrm{~mL} / \mathrm{min}$ and the overtone number $n=3,5$. Considering that the bulk solution was dilute, its density $\left(\rho_{l}\right)$ and viscosity $\left(\eta_{l}\right)$ were taken to be those of water, that is, $\rho_{l} \sim 1000 \mathrm{~kg} / \mathrm{m}^{3}$ and $\eta_{l} \sim 1 \times 10^{-3} \mathrm{~Pa} \cdot \mathrm{s}$, respectively. The density $\left(\rho_{f}\right)$ of the grafted PAA layer is estimated to be $\sim 1000 \mathrm{~kg} / \mathrm{m}^{3}$ as a fixed value in the fitting. Clearly, $\Delta f$ and $\Delta D$ fit by the Voigt model agree well with the experimental results. As revealed before, ${ }^{14}$ the thickness obtained from the Voigt model is in consistent with that measured by ellipsometry. Accordingly, the thickness, shear viscosity and elastic shear modulus of the brushes fit by Voigt model are reasonable. Such parameters are important for the applications of a nanofilm. ${ }^{23,24}$

Figure 6 shows the changes of thickness $\left(\Delta t_{f}\right)$, shear viscosity $\left(\eta_{f}\right)$ and elastic shear modulus $\left(\mu_{f}\right)$ of PAA brushes estimated by the Voigt model. Due to the stretching and collapse of PAA brushes, $\Delta t_{f}$ oscillates between $\mathrm{pH} 3.2$ and 6.6 with amplitude of $\sim 2 \mathrm{~nm}$. This agrees with the previous result where the PAA brushes were stimulated by different $\mathrm{pH}$ solutions. ${ }^{25}$ At the same time, $\eta_{f}$ and $\mu_{f}$ also exhibit oscillations with the change of $\mathrm{pH}$. As $\mathrm{pH}$ increases from 3.2 to $6.6, \eta_{f}$ increases from $\sim 1.0 \times 10^{-3}$ to $\sim 2.7 \times 10^{-3} \mathrm{~Pa} \cdot \mathrm{s}$ due to the hydration of PAA chains. On the other hand, the increase of electrostatic repulsion between PAA chains with $\mathrm{pH}$ varied from 3.2 to 6.6 leads PAA brushes to adopt a weakly compressible state, so that $\mu_{f}$ increases from $\sim 1.0 \times 10^{4}$ to $\sim 2.8 \times 10^{5} \mathrm{~Pa}$. In contrast, $\eta_{f}$ and $\mu_{f}$ decrease 


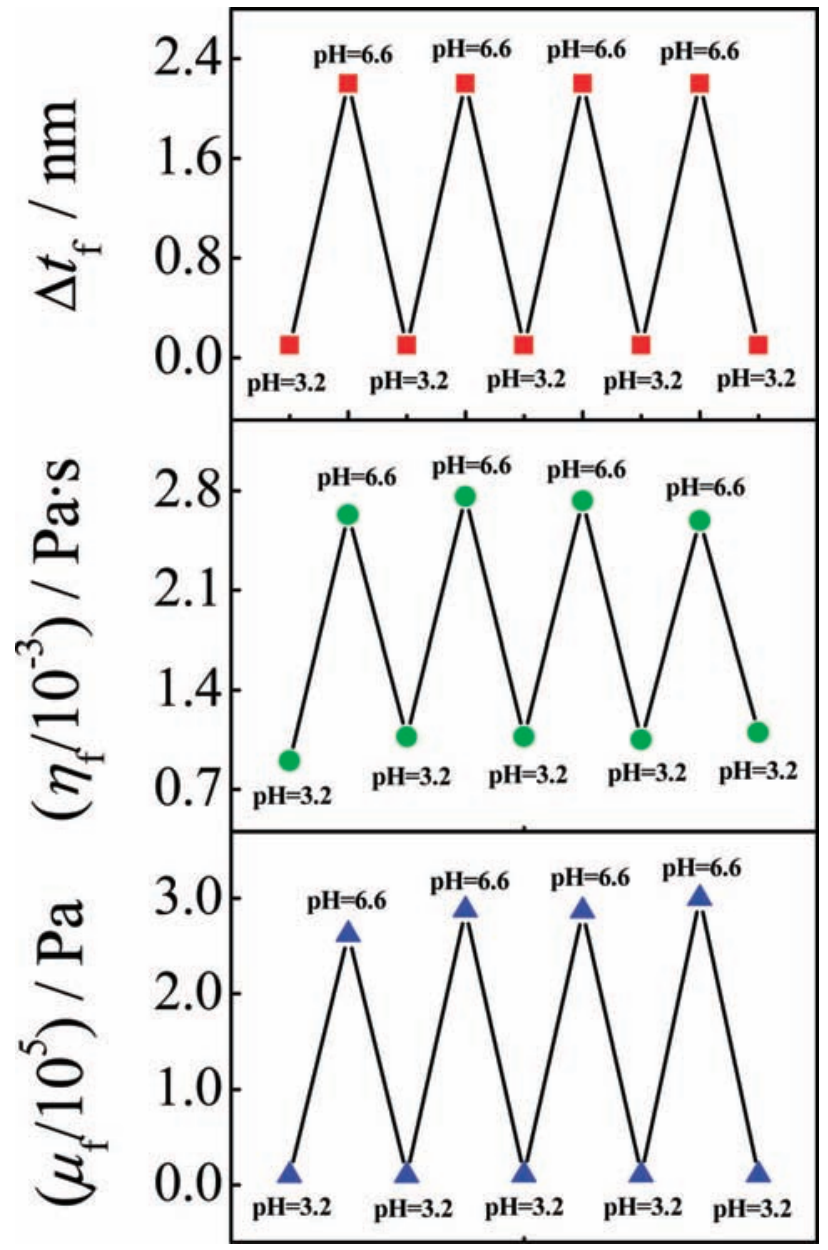

Figure 6. Changes of thickness $\left(\Delta t_{f}\right)$, shear viscosity $\left(\eta_{f}\right)$ and elastic shear modulus $\left(\mu_{f}\right)$ of PAA brushes under the oscillation of $\mathrm{pH}$.

with the decreasing $\mathrm{pH}$. Clearly, the time dependence of periodic changes of the characteristic parameters of PAA brushes as a function of $\mathrm{pH}$ indicates that the solid/liquid interface has a reciprocating switching behavior. Many biological systems such as cell division cycle are controlled by oscillations in $\mathrm{pH} .^{26,27}$ The present study can serve as a model for understanding the dynamics of the more complex biological system. It can also help us to develop smart nanodevices, controlled drug delivery system and artificial organs.

\section{Conclusion}

We have investigated the $\mathrm{pH}$ induced oscillation of PAA brushes under a continuous flow of BSF solution by use of QCM-D in situ. The changes in $\Delta f$ and $\Delta D$ as a function of time clearly indicate the oscillation of PAA brushes. The periodic changes in thickness, shear viscosity and elastic shear modulus of the brushes further demonstrate the oscillation of the interfacial properties. Considering that solid/liquid interface extensively exists in living systems and industrial systems, the brushes may be used in the artificial organs, water antipollution techniques and nanodevices.
Acknowledgment. The financial support of the National Distinguished Young Investigator Fund (20725414) and Ministry of Science and Technology of China (2007CB936401) is acknowledged.

Supporting Information Available: Figures showing the changes of frequency and dissipation for QCM-D resonator without PAA brushes in BSF solution and the oscillations of $\mathrm{pH}$ and PAA brushes at $V_{f r}=1.0 \mathrm{~mL} / \mathrm{min}$. This material is available free of charge via the Internet at http://pubs.acs.org.

\section{References and Notes}

(1) Zhou, F.; Shu, W. M.; Welland, M. E.; Huck, W. T. S. J. Am. Chem. Soc. 2006, 128, 5326.

(2) Konradi, R.; Rühe, J. Macromolecules 2005, 38, 4345.

(3) (a) Yoshida, R.; Takahashi, T.; Yamaguchi, T.; Ichijo, H. J. Am. Chem. Soc. 1996, 118, 5134. (b) Takeoka, Y.; Watanabe, M.; Yoshida, R. J. Am. Chem. Soc. 2003, 125, 13320. (c) Sakai, T.; Yoshida, R. Langmuir 2004, 20, 1036.

(4) Yoshida, R.; Sakai, T.; Ito, S.; Yamaguchi, T. J. Am. Chem. Soc. 2002, 124, 8095 .

(5) Ito, Y.; Hara, Y.; Uetsuka, H.; Hasuda, H.; Onishi, H.; Arakawa, H.; Ikai, A.; Yoshida, R. J. Phys. Chem. B 2006, 110, 5170.

(6) Yoshida, R.; Yamaguchi, T.; Ichijo, H. Mater. Sci. Eng., C 1996, 4, 107.

(7) (a) Crook, C. J.; Smith, A.; Jones, R. A. L.; Ryan, A. J. Phys. Chem. Chem. Phys. 2002, 4, 1367. (b) Howse, J. R.; Topham, P.; Crook, C. J.; Gleeson, A. J.; Bras, W.; Jones, R. A. L.; Ryan, A. J. Nano Lett. 2006, 6, 73. (c) Wang, L.; Topham, P. D.; Mykhaylyk, O. O.; Howse, J. R.; Bras, W.; Jones, R. A. L.; Ryan, A. J. Adv. Mater. 2007, 19, 3544. (d) Topham, P. D.; Howse, J. R.; Crook, C. J.; Armes, S. P.; Jones, R. A. L.; Ryan, A. J. Macromolecules 2007, 40, 4393.

(8) (a) Liedl, T.; Simmel, F. C. Nano Lett. 2005, 5, 1894. (b) Liedl, T.; Olapinski, M.; Simmel, F. C. Angew. Chem., Int. Ed. 2006, 45, 5007.

(9) Tuguhu, S.; Arnold, A.; Sielaff, I.; Johnsson, K.; Klok, H. A. Biomacromolecules 2005, 6, 1602.

(10) Guo, X.; Ballauff, M. Langmuir 2000, 16, 8719.

(11) Ito, Y.; Park, Y. S.; Imanishi, Y. J. Am. Chem. Soc. 1997, 119, 2739.

(12) Prokhorova, S. A.; Kopyshey, A.; Ramakrishnan, A.; Zhang, H.; Rühe, J. Nanotechnology 2003, 14, 1098.

(13) Yessine, M. A.; Leroux, J. C. Adv. Drug. Deliv. Rev. 2004, 56, 999.

(14) HööK, F.; Kasemo, B.; Nylander, T.; Fant, C.; Sott, K.; Elwing, H. Anal. Chem. 2001, 73, 5796.

(15) Rodahl, M.; Höök, F.; Krozer, A.; Kasemo, B.; Breszinsky, P. Rev. Sci. Instrum. 1995, 66, 3924.

(16) Sauerbrey, G. Z. Phys. 1959, 155, 206.

(17) Bottom, V. E. Introduction to Quartz Crystal Unit Design; Van Nostrand Reinhold Co.: New York, 1982.

(18) Dong, R.; Krishnan, S.; Baird, B. A.; Lindau, M.; Ober, C. K. Biomacromolecules 2007, 8, 3082 .

(19) Voinova, M. V.; Rodahl, M.; Jonson, M.; Kasemo, B. Phys. Scrip. 1999, 59, 391.

(20) Sankhe, A. Y.; Husson, S. M.; II, S. M. K. Macromolecules 2006, 39, 1376.

(21) Martin, S. J.; Frye, G. C.; Ricco, A. J.; Senturia, S. D. Anal. Chem. 1993, $65,2910$.

(22) Gebhardt, J. E.; Fuerstenau, D. W. Colloids Surf. 1983, 7, 221.

(23) Picart, C.; Sengupta, K.; Schilling, J.; Maurstad, G.; Ladam, G.; Bausch, A. R.; Sackmann, E. J. Phys. Chem. B 2004, 108, 7196.

(24) Lukkari, J.; Salomäki, M.; Ääritalo, T.; Loikas, K.; Laiho, T.; Kankare, J. Langmuir 2002, 18, 8496.

(25) Treat, N. D.; Ayres, N.; Boyes, S. G.; Brittain, W. J. Macromolecules 2006, 39, 26.

(26) Dolnik, M.; Gardner, T. S.; Epstein, I. R.; Collins, J. J. Phys. Rev. Lett. 1999, 82, 1582 .

(27) Gray, N. S; Wodicka, L.; Thunnissen, A. W. H.; Norman, T. C.; Kwon, S.; Espinoza, F. H.; Morgan, D. O.; Barnes, G.; LeClerc, S.; Meijer, L.; Kim, S.; Lockhart, D. J.; Schultz, P. G. Science 1998, 281, 533.

JP801533R 